\title{
Сучасні методичні підходи у тренувальному процесі юних тенісистів
}

Надія Кіченок

Дніпровський державний інститут фізичної культури і спорту, Дніпро, Україна

problems and prospects. Sportyvnyi visnyk Prydniprovia. 2013;1:18-22.

9. International Fencing Federation (FIE). [Internet] 2021 [cited 2021 Oct 07] Available from: https://fie.org/.

Надійшла 16.09.2021

Анотація. Одним із завдань тренера з тенісу є поступове підвищення ефективності гри юного спортсмена. Для його реалізації застосовують ряд методів і стратегій тренування, що передбачають використання різних засобів загальнопедагогічного, спеціального спортивного та технічного характеру. Мета. Вивчення методичних особливостей сучасної підготовки юних тенісистів. Методи. Аналіз наукової та методичної літератури. Результати. Перспективними методологічними підходами у навчально-тренувальному процесі юних гравців слід вважати оптимізацію фрізичної та техніко-тактичної підготовки із застосуванням інтегрального, колового та фрітнес-тренування, а також використання сучасних технічних засобів, спрямованих на покращення освоєння спеціальних рухових навичок тенісистів, забезпечення контролю та зворотного зв'язку в тренувальному процесі, а також таких, що доповнюють процес підготовки. Розробка методології тренінгу з тенісу виражається у формі альтернативних стилів тренувань або у використанні нових інструментів та обладнання. У випадку есрективності такі підходи впливають на тренерську практику і можуть покращити тренувальний процес. Проте в плані вдосконалення підготовки юних тенісистів необхідно звертати увагу на нововведення, враховуючи особливості розвитку дитячого організму, фрормування тенісних навичок та відповідність обраних засобів кінематичному зразку рухової дії. Ключові слова: юні тенісисти, методика тренування, спортивна підготовка.

\section{Nadiia Kichenok}

\section{MODERN METHODOLOGICAL APPROACHES IN THE TRAINING PROCESS OF YOUNG TENNIS PLAYERS}

Abstract. One of the objectives of a tennis coach is to gradually increase the playing efficiency of a young athlete. To achieve it, a number of training methods and strategies are used, which involve the use of various general pedagogical and specific sports and technical means. Objective. To study methodological characteristics of modern training of young tennis players. Methods. Analysis of scientific and methodological literature. Results. Methodological approaches in the training process of young tennis players that should be considered as promising ones are the follows: optimization of physical, technical, and tactical training through the use of integrated, circuit, and fitness training; and the use of modern technical means focused on improving the development of special motor skills in tennis players, providing control and feedback in the training process, as well as those that complement the training process. The development of tennis training methodology is expressed in the form of alternative training styles or in the use of new tools and equipment. If effective, such approaches affect coaching practice and can improve the training process. However, in terms of improving young tennis players training, it is necessary to pay attention to innovations that take into account the peculiarities of the child's body, the formation of tennis skills, and matching of selected means to the kinematic pattern of a motor action.

Keywords: young tennis players, methodology of training, sports training.

Kichenok N. Modern methodological approaches in the training process of young tennis players. Theory and Methods of Physical education and sports. 2021; 3: 28-31 DOI: 10.32652/tmfvs.2021.3.28-31
Кіченок Н. Сучасні методичні підходи у тренувальному процесі юних тенісистів. Теорія і методика фрізичного виховання і спорту. 2021; 3: 28-31

DOI: 10.32652/tmfvs.2021.3.28-31
Вступ. Сучасна спортивна підготовка передбачає узгодження традиційних підходів і нововведень, в основі яких лежить використання модифікованого обладнання та різних технічних пристосувань. Їх поєднання дозволяє збільшити кількість корисної інформації про динаміку тренованості юних спортсменів, а також фрормує ефективний зворотний зв'язок для всіх учасників процесу підготовки. Поява сучасних приладів контролю та обліку, спрощення або утруднення умов тренування спортсменів потребують ретельного аналізу перед тим, як вони будуть застосовані в тренувальному процесі юнаків та дівчат. Проте, вже сьогодні розробляється модифіковане обладнання суто для використання в підготовці юних тенісистів. Відтак постає необхідність аналізу та узагальнення сучасних уявлень про особливості тренувального процесу юних гравців у теніс з урахуванням застосування сучасних тренувальних засобів.

Структура підготовки юних тенісистів $€$ усталеною й узгоджується з положеннями теорії та методики юнацького спорту. Проте, через зміни, пов'язані зі збільшенням ігрової практики юних гравців вже у ранньому віці, тренувальна діяльність у тенісі характеризується спеціалізованістю підготовки [8]. Цей процес ускладнюється 3 огляду на індивідуальний характер тенісу, коли гравець може розраховувати лише на власні сили, щоб досягти результату, що створює значний психологічний тиск на організм дитини, який лише формується. Відповідно, виникає потреба у пошуку таких методичних підходів у тренуванні, які могли б зробити процес набуття юнаками та дівчатами тенісних навичок більш ефективним та узгоджува- 
лися 3 потребами забезпечення збереження здоров'я.

Сьогодні шляхами вирішення оптимізації навчально-тренувального процесу юних гравців слід вважати оптимізацію фрізичної та технікотактичної підготовки із застосуванням інтегрального, колового та фрітнестренування, а також використання сучасних технічних засобів, спрямованих на покращення освоєння спеціальних рухових навичок тенісистів, забезпечення контролю та зворотного зв'язку в тренувальному процесі, а також таких, що доповнюють процес підготовки $[2,4]$.

Мета дослідження - вивчення методичних особливостей сучасної підготовки юних тенісистів.

Методи дослідження: аналіз науково-методичної літератури.

Результати дослідження та їх обговорення. Для пошуку актуальних досліджень за темою публікації було використано електронні бази Scholar Google, Scopus, Web of Science. Ключовими словами та фразами під час пошуку були такі: «методика підготовки юних тенісистів», «методи навчання у тенісі», «training of young tennis players», «methodology for training young tennis players». Серед 78 знайдених публікацій у рецензованих наукових виданнях було відібрано 19, які відповідали меті дослідження. Статті, піддані аналізу, були як оглядовими, так і містили оригінальні дослідження.

Через збільшення кількості змагань юних тенісистів зменшується час, що відводиться на розвиток їхніх фізичних здібностей. При цьому акцент підготовки зосереджений на засвоєнні гравцями спеціалізованих тенісних навичок, що не сприяє створенню необхідної бази загальної фрізичної підготовленості. Однак для організму, що формується, це має важливе значення і в подальшому може позначитися на спортивній результативності. Вочевидь, має змінюватися і традиційний підхід до розвитку фрізичних якостей юних тенісистів. Для вирішення цього питання ефективним, за результатами досліджень I. I. Yevtyfiieva et. al. [18], є програмування техніко-тактичної підготовки тенісистів за блоковою системою, за якою акцентовано увагу на її підготовці в інтеграції з розвитком функціональних можливостей та психофрізіологічних функцій юних тенісистів $з$ урахуванням індивідуального підходу. Такої самої думки дотримуються Z. Kozina et al., які виявили індивідуально-фракторну структуру підготовленості юних гравців, на основі якої слід формувати індивідуальні програми навчання, поєднуючи розвиток технічної, тактичної, фрізичної підготовленості разом з розвитком когнітивних і психофізіологічних функцій [15].

В інших випадках учені пропонують комплексні програми вдосконалення методики тренування юних гравців. Так, S. Yildiz et. al. [19] представили варіант функціонального тренування, що складається 3 рухів, які спортсмен буде виконувати в трьох площинах для м'язів, котрі використовуються в техніці удару: поштовх, тяга, обертання, присідання, підйом і стрибок, вправи для балансу, еластичні стрічки, медболи. Натомість А. О. Прокопенко, Н. О. Константиновська [5] пропонують для розвитку в підготовці юних тенісистів використовувати рухливі ігри, які також сприяють фрормуванню мотивації до занять. Іншим ефективним засобом підготовки юних тенісистів, за свідченням С. В. Трачука та ін. [7], є заняття міні-тенісом із використанням колового методу тренування, що дає можливість створити кращі умови як для комплексного розвитку фізичних здібностей, так і навчання технічних прийомів, підвищуючи моторну щільність занять.

Інноваційну методику - фрітнестеніс - для поліпшення загальної фрізичної підготовки юних тенісистів пропонують Л. В. Морозова та ін. [3] з використанням елементів степаеробіки, босу-платформи, фрітболів, варіацій переміщень по корту, стретчингу та слайд-платформи. Запропонована програма органічно поєднується із вправами на освоєння основних технічних рухів тенісистів. Динь Хунг Чионг [1] виявив ефективний шлях підвищення якості навчання юних тенісистів, запропонувавши розподіляти тренувальні завдання за способами: простих повторень технічної дії у стандартних умовах; наближених завдань, коли перші повторення виконуються за одними характеристиками, що в подальших спробах поступово змінюються.

Дослідники шукають способи покращення методики тренування юних тенісистів через розробку та застосування методик, які мають комплексний або інтегральний вплив на розвиток фрізичних якостей та спеціальних здібностей юних гравців. Також слід враховувати індивідуальні особливості тих, хто займається.

Відомо, що вік пов'язаний зі стадією рухового розвитку, на якій знаходиться дитина. Засвоєння спеціалізованих рухів, притаманних тенісу, перш ніж у дітей сфрормуються зрілі форми основних рухових навичок, може негативно позначитися на подальшому спортивному вдосконаленні [11]. Молоді гравці змушені намагатися робити те, до чого вони не готові фрізично. Таким чином, у дитячому та юнацькому спорті під час пошуку комфрортності стану дитини знаходить застосування теорія розвитку ергономічних систем [9]. Коли комфортність під час розвитку системи «дитина-ракетка-м'яч-корт» досягається на основі використання принципу відповідності або подібності (наприклад, підбір інвентарю, снарядів і їх елементів, що входять у систему). Властивості і якості (за антропометричними, фізичними, психофізіологічними показниками), що розвиваються, повинні відповідати своєму прототипу, тобто професійній системі [10]. В такому випадку система буде ергономічною, а юний спортсмен збереже здоров'я і буде успішно розвиватися. Таким чином, на етапі початкової підготовки в тенісі підбір ракеток, м'ячів і кортів стає найважливішим завданням тренера. J. M. Gimenez-Egido et. al. [14] виявили позитивний вплив модифікованого тенісного обладнання та ігрових майданчиків на полегшення процесу навчання юних тенісистів основних технічних прийомів.

Через призму тренера використання модифікованого обладнання є цінним інструментом для розвитку навичок. Застосування методик кооперативного стилю навчання, демонстра- 
ції діяльності та підходу, заснованого на обмеженнях, відповідає рекомендованим стратегіям навчання юних спортсменів.

Сучасний теніс розглядають як спортивне мистецтво, де кожен удар виконується по-різному, а гравець бере участь у процесі «сприйняття-рішення-дія-зворотний зв'язок». Поліпшення цього процесу можливе на основі використання інтерактивних технологій [6]. Так, Чжан Сяоцюань [9] запропонував використовувати пристрої GPS як інструмент для кількісного оцінювання навантаження на гравців як під час тренувань, так і в ході матчу, а також з метою поліпшення результатів тенісистів за рахунок адаптації конкретних тренувань до індивідуальних фрізичних потреб. M. Chalakov [12] зазначає, що використання відеозаписів і їх аналіз спільно з тенісистами будуть перевагою для тренувального процесу і поліпшать візуальне сприйняття руху на корті, а також виконання фраз ударів. Це узгоджується 3 думкою L. García-González et al. [13], що завдяки вдосконаленню навичок прийняття рішень і виконання допомагає юним спортсменам навчитися приймати рішення в умовах, які вимагає їхня особиста спортивна діяльність, допомагає їм передбачати події на корті. Таким чином, використання аудіо-візуальних технічних засобів $\epsilon$ перспективним шляхом вдосконалення методики тренування юних гравців.

P. Le Noury et. al. [16] досліджували можливості використання середовища VR для моделювання гри в теніс та виявили, що віртуальна гра забезпечує повне занурення у процес та може бути корисною і цікавою для тренування юних гравців. L. Šlosar et. al. [17] рекомендують використовувати віртуальні ігрові навантаження як додатковий інструмент тренування, спрямований на вдосконалення важливих когнітивно-рухових навичок тенісу шляхом додавання динаміки до стандартизованого тренувального процесу. Проте залишається небезпека використання віртуальних середовищ, що може призводити до засвоєння неправильної навички. Але віртуальні персонажі і середовище дійсно мають ширший діапазон доступ- них функцій, головним чином тому, що зроблене колись відео незмінне в реальному часі, тоді як віртуальне середовище може реагувати на дії користувача і змінювати положення під час гри.

Висновки. Аналіз і узагальнення даних спеціальної науково-методично літератури свідчать, що традиційна сучасна система спортивної підготовки юних тенісистів 3 використанням різних методичних підходів до навчання повною мірою дозволяє вирішити завдання, орієнтовані на формування ефективної техніки та належного рівня розвитку фрізичних здібностей. Основними чинниками оптимізації рухової програми в тенісі $€$ техніка ударних дій і переміщень по корту. Складність розробки тренувальних завдань полягає у тому, що на реалізацію технічного прийому в теніс впливає рішення тих чи інших тактичних завдань, характерних для даного моменту гри.

Часові обмеження ставлять тренерів і спортсменів в умови, коли потрібно навчити більше, ніж одного руху за тренування. Існує складність у розмаїтті підготовки, яку непросто подолати за допомогою звичайних тренувальних засобів. Тому збільшується запит на застосування сучасних технічних розробок. Велике значення має процес підвищення комфорту та ефективності навчання техніки гри юних тенісистів, що сприятиме збереженню здоров'я й успішному розвитку.

Перспективи подальших досліджень передбачають розробку та апробацію комплексної методики підготовки юних тенісистів на основі сучасних тенденцій.

Конфлікт інтересів. Автор заявляє що відсутній будь-який конфлікт інтересів.

\section{ЛITEPATУРA}

1. Динь Хунг Чыонг. Применение комплексного метода подготовки начинающих тенниси стов. Физическая культура: воспитание, образование, тренировка. 2013;2:46-48.

2. Лапицький ВО, Міщенко ОВ, Скрипка IM. Обґрунтування ефективності методики тренувального процесу юних тенісистів. Вісник Чернігівського національного педагогічного університету. Серія: Педагогічні науки. Фізичне виховання та спорт. 2017;2 (147):192-194.

3. Морозова ЛВ, Медведев АВ, Савенков ГИ Факторы, определяющие необходимость ис- пользования фитнес-тенниса для улучшения общефизической подготовки юных теннисистов. Ученые записки университета им. П. Ф. Лесгафта. 2019;7(173):131-133.

4. Ноздрачева АВ, Степанова МЕ. Сравнительный анализ подготовки юных теннисистов в различных странах мира. Актуальные научнометодические проблемы подготовки спортсменов в игровых видах спорта: материалы Всерос. научно-практ. конф. с международным участием; 2019.97-99.

5. Прокопенко АО, Константиновська НО. Особливості використання рухливих ігор на етапі початкової підготовки тенісистів. Перспективи, проблеми та наявні здобутки розвитку фрізичної культури і спорту в Україні: матеріали IV Всеукр. електрон. конф. «COLOR OF SCIENCE». Вінниця; 2021.239-242.

6. Собко ІМ, Улаєва ЛО, Кушнір ЮВ. Застосування технічних пристроїв у тренувальному процесі тенісистів початкового етапу навчання. Технології збереження здоров'я, реабілітація і фрізична терапія: зб. статей XII Міжнар. наук. конф. Харків-Торунь; 2019.196-200.

7. Трачук СВ, Давиденко ЕВ, Савельєва АВ Особливості організації та використання засобів міні-тенісу у фізичному вихованні молодших школярів. Слобожанський науково-спортивний вісник. 2012;3:42-46

8. Чехівська ЮС, Гуренко ОА. Особливості етапів тренувального процесу в багаторічній підготовці тенісистів. Науковий часопис НПУ імені М.П. Драгоманова. 2020;3(123):168-172.

9. Чжан Сяоцюань. Начальная подготовка детей 6-10 лет в теннисе на основе эргономического подхода [диссертация]. Санкт-Петербург; 2012. $146 \mathrm{c}$

10. Якубовский ВС, Якубовский ГС, Иванова ТС. Адаптационные изменения в детском теннисе по программе международной теннисной ассоциации ITF «10 и младше». Физическая культура: образование, воспитание, тренировка. 2012;6:71-72

11. Anderson K. United States tennis association project $36 / 60$. Coaching \& Sport Science Review. 2007;42:17.

12. Chalakov M. Optimizing the control of technical performance of forehand stroke among 12-year old tennis players using martin's sigma method. Trakia Journal of Sciences. 2020;18:682688.

13. García-González L, Moreno A, Gil A, Moreno M, Villar F. Effects of Decision Training on Decision Making and Performance in Young Tennis Players: An Applied Research. Journal of Applied Sport Psychology. 2014;26:426-440.

14. Gimenez-Egido JM, Ortega-Toro E, Palao JM, Verdú-Conesa I, Torres-Luque G. Effect of Modification Rules in Competition on Technical-Tactical Action in Young Tennis Players (Under-10). Frontiers in psychology. 2020;10:2789.

15. Kozina Z, Yevtyfiieva I, Muszkieta R, Krzysztof P, Podstawski R. General and individual factor structure of complex preparation of young tennis players of $10-12$ years. Journal of Physical Education and Sport. 2020;20:1242-1249.

16. Le Noury P, Buszard T, Reid M, Farrow D. Examining the representativeness of a virtual reality environment for simulation of tennis performance. Journal of Sports Sciences. 2021:4:412-420.

17. Šlosar L, de Bruin ED, Fontes EB, Plevnik M, Pisot $R$, Simunic B, Marusic U. Additional Exergames to Regular Tennis Training Improves Cognitive-Motor Functions of Children but May Temporarily Affect Tennis Technique: A 
Single-Blind Randomized Controlled Trial. Frontiers in psychology. 2021;12:611382.

18. Yevtyfiieva II, Korobeinik VA, Kolisnychenko AO. The influence of training loads of technical and tactical training on the cardiovascular system of tennis players 10-12 years. Health, sport, rehabilitation. 2020;5(4):23-32.

19. Yildiz S, Pinar S, Gelen E. Effects of 8-Week Functional vs. Traditional Training on Athletic Performance and Functional Movement on Prepubertal Tennis Players. Journal of strength and conditioning research. 2019;33(3):651-661.

\section{LITERATURE}

1. Din Hung Tchuong. The use of an integrated method of training beginner tennis players Fizicheskaya kultura: vospitanie, obrazovanie, trenirovka. 2013;2:46-48.

2. Lapytckyi VO, Mishchenko OV, Skrypka IM. Substantiation of efficiency of a methodology of training process of young tennis players. Bulletin of the Chernihiv National Pedagogical University. Series: Pedagogical Sciences. Physical education and sports. 2017;2 (147):192-194.

3. Morozova LV, Medvedev AV, Savenkov GI. Factors determining the need to use fitness-tennis to improve the general physical preparedness of young tennis players. Uchenye zapiski universiteta imeni P.F. Lesgafta. 2019;7(173):131-133.

4. Nozdracheva AV, Stepanova ME. Comparative analysis of young tennis players training in different countries of the world. Actual scientific and methodological issues of training athletes in team sports: Proceedings of the All-Russian scient. pract. conf. with internat. participation 2019.97-99

5. Prokopenko AO, Konstantinovska NO. Features of the use of active games at the stage of basic training of tennis players. Prospects, issues, and current achievements in the development of physical culture and sports in Ukraine: Proceedings of the IVth All-Ukrainian Internet conference «COLOR OF SCIENCE». Vinnytsia: 2021.239-242.

6. Sobko IM, Ulaieva LO, Kushnir YuV. The use of technical aids in the training process of tennis players at the basic stage of training. Healthmaintenance technologies, rehabilitation and physical therapy: Coll. of papers of the XII Internat. scient. conf. Kharkiv-Torun; 2019.196-200.
7. Trachuk SV, Davydenko EV, Saveliieva AV The features of the organization and use of minitennis in the physical education of primary school students. Slobozhanskyi naukovo-sportyvnyi visnyk. 2012;3:8. Chekhivska YuS, Gurenko OA, Tomenko OA. The features of the stages of training process in the long-term preparation of tennis players. Naukovyi chasopys M.P.Dragomanov National Pedagogical University. 2020;3(123):168172.

9. Zhang Xiaoquan. Basic training of $6-$ 10-year-old children in tennis based on an ergonomic approach [dissertation]. Saint Petersburg; 2012. $146 \mathrm{p}$.

10. Yakubovskiy VS, Yakubovskiy GS, Ivanova TS. Adaptation changes in children's tennis under the program of the International Tennis Federation (ITF) «10 and under». Fizicheskaya kultura: vospitanie, obrazovanie, trenirovka. 2012;6:71-72.

11. Anderson K. United States tennis association project 36/60. Coaching \& Sport Science Review. 2007;42:17

12. Chalakov M. Optimizing the control of technical performance of forehand stroke among 12-year old tennis players using martin's sigma method. Trakia Journal of Sciences. 2020;18:682688.

13. García-González L, Moreno A, Gil A, Moreno M, Villar F. Effects of Decision Training on Decision Making and Performance in Young Tennis

\section{ІНФОРМАЦІЯ ПРО АВТОРА}

Кіченок Надія Вікторівна kichenoknadiia@i.ua

Дніпровський державний інститут фізичної культури і спорту

м. Дніпро

Women's Tennis Association (WTA)

100 Second Avenue South Suite 1100-S, St. Petersburg, FL 33701

\section{INFORMATION ABOUT THE AUTHOR}

Kichenok Nadiia kichenoknadiia@i.ua

Dnipro Power Institute of Physical Culture and Sports

Dnipro

Women's Tennis Association (WTA)

100 Second Avenue South Suite 1100-S, St. Petersburg, FL 33701 